\title{
Demographic, Clinical and Hormonal Characteristics as Predicting Factors Affecting the Outcome of Laparoscopic Ovarian Drilling in Women with Poly Cystic Ovary Syndrome
}

\author{
Shelan Omar Jaafar'1, Ghada Saadulla Alsakkal ${ }^{2}$, Namir Ghanim Al-Tawil ${ }^{3}$ \\ ${ }^{1}$ Assistant Lecturer, PhD Student, ${ }^{2}$ Assistant Professor, Department of Obstetrics and Gynecology, College of \\ Medicine, Hawler Medical University, Erbil, Iraq, ${ }^{3}$ Full Professor, Department of community medicine, College of \\ Medicine, Hawler Medical University, Erbil, Iraq
}

\begin{abstract}
Background: Laparoscopic ovarian drilling as a second line of treatment modality for those PCOS patients failed to respond to clomophine citrate they may have the benefit of avoiding the side effects of long term drug therapy, lower costs and less time for successful ovulation and conceprtion compared to medical treatment. Objectives: Before doing LOD recognize factors that affect the outcome of the procedure for selecting patients to avoid unnecessary or unbeneficial intervention. Method: 143 anovulatory infertile PCOS patients followed up for 6 months after LOD for ovulation with pre-operative assessment for demographic characters and serum hormone levels (LH, FSH, free testosterone, AMH and prolactin). Results: Ovulation was demonstrated in 59.4\%. Regression analysis showed significantly higher rates of ovulation among women $<5$ years duration of infertility $(\mathrm{OR}=3.35,95 \% \mathrm{CI}=1.47-7.65), \mathrm{LH}>12 \mathrm{mIU} / \mathrm{ml}(\mathrm{OR}=4.18,95 \%$ $\mathrm{CI}=1.28-13.63)$ and free testosterone $<4.5 \mathrm{ng} / \mathrm{ml}(\mathrm{OR}=3.22,95 \% \mathrm{CI}=1.08-9.59)$. No significant $(\mathrm{p}=$ 0.078 ) association was detected between the ovulation rate and the AMH level, but it is evident that the OR was around 2 among women with AMH level of less than $7.7 \mathrm{ng} / \mathrm{ml}$.
\end{abstract}

Conclusion: preoperative $\mathrm{LH}$, free testosterone and duration of infertility regarded as 3 important predicting factor for success of LOD

Keywords: PCOS:polycystic ovary syndrome; LOD: laparoscopic ovarian drlling, Ovulation.

\section{Introduction}

Polycystic ovary syndrome (PCOS) is one of the most prevalent endocrinopathies affecting about 5-10 $\%$ women of reproductive age group. There is a great controversies regarding the diagnosis and mode of treatment of this syndrome ${ }^{1}$, although experts have been succeeded to develop a universally accepted criteria for diagnosis of $\operatorname{PCOS}^{2}$ but adoption of optimal treatment had not yet reached. Wedge resection of ovary which is first described by Stein and Leventhal ${ }^{3}$ for treating anovulation by laparotomy has been developed to less traumatic ovarian surgery through the laparoscope by Gjonnaess ${ }^{4}$. LOD is currently recommended as an

\section{Corresponding Author:}

Shelan Omar Jaafar

Email: shilanoj@gmail.com alternative second line approach, safe and cost effective to gonadotropins for those with anovulatory infertility, without the risk of multiple pregnancy and ovarian hyperstimulation $^{5}$, still there is no well-established mechanism of action of LOD and therefore we can not exactly answer the question why some PCOS patients not responding to this treatment ${ }^{6}$, and it is not known whether it will exerts it is effect directly on the ovary or through systemic endocrine pathway ${ }^{7}$, it may act by destroying ovarian androgen-producing tissue and reducing the peripheral conversion of androgens to estrogens. However, others believe that ovarian diathermy works by increasing the sensitivity of the ovaries to endogenous FSH, and that only a minimal amount of thermal injury is required ${ }^{8}$. A fall in the serum levels of androgens and $\mathrm{LH}$ and an increase in $\mathrm{FSH}$ levels have been demonstrated after ovarian drilling ${ }^{9}$, 
The aim of the present study was to identify some of the factors that affect the outcome of LOD for improvement of success in women with PCOS for better selection of the patients that get benefit from this intervention and avoidance of unbeneficial surgery.

\section{Materials and Method}

The current study followed 143 subfertile women with anovulation failed to respond to oral medical therapy (persistant anovulation despite maximum dose of oral therapy for up to 6 cycles) consulting the outpatient gynaecology and fertility clinic in Maternity Teaching Hospital, public maternity hospital in Erbil, Iraq from September 2016 to July 2018, All included patients in the study diagnosed to have PCOS based on Rotterdam criteria include at least two of the three criteria: oligo-anovulation, clinical and /or biochemical evidence of hyperandrogenism, and sonographic features of polycystic ovaries ${ }^{2}$. Written informed consent was obtained from each participant after explaining the study purpose, procedures and follow up time. Those associated with tubal and male factors infertility, endocrine disorders (thyroid disease, cushing s syndrome and androgen secreting tumor) $\mathrm{AMH}<$ $4 \mathrm{ng} / \mathrm{ml}$ and $\mathrm{FSH}>12.5 \mathrm{mIU} / \mathrm{ml}$ are all excluded from the study. All enrolled women underwent transvaginal ultrasound preoperatively.

Preoperatively baseline hormones were measured at the day 2-4 of cycle for serum levels of $\mathrm{LH}, \mathrm{FSH}$, testosterone, SHBG, AMH and prolactin, the LH:FSH ratio and FAI calculated. Serum hormone levels were measured by Elecsys machine (Roche Diagnostics, Hitachi, Switzerland) for determination of human $\mathrm{LH}$, FSH, testosterone, prolactin and SHBG levels. AMH was measured by Enzyme linked immunosorbent assay (ELISA) kit.

After cycle in the proliferative phase ( progesterone induced withdrawal bleed or spontaneous) LOD performed by or in the presence of first author to ensure that the same technique was used for each patient by a laparoscope (Karl Storz, Germany) with assessment of tubal patency with methylene blue and macroscopically uterus, tubes and ovaries were examined. The technique described by ${ }^{9}$ four punctures performed per ovary, each for $4 \mathrm{~s}$ to a depth of 4-6 mm, a monopolar coagulating electrical current at $40 \mathrm{~W}$ power setting used, at the end of the procedure pelvis was irrigated with lactated Ringer's solution and $500 \mathrm{cc}$ was left intraperitoneally. Ovulation and pregnancy followed up to 6 months(ovulation defined as the presence of at least one mature graffian follicle measuring $\geq 18 \mathrm{~mm}$ by transvaginal ultrasound and serum progesterone level at the day of 21 as indicators of ovulation (serum progesterone level $\geq 13 \mathrm{nmol} / 1$ was considered a strong indication for ovulation ${ }^{10}$.

\section{Statistical analysis}

Data were analyzed using the Statistical Package for Social Sciences (SPSS, version 22). Student's t test of two independent samples was used to compare means of two groups. Chi square test of association was used to compare between proportions. When the expected count of more than $20 \%$ of the cells of the table was $<5$, Fisher's exact test was used. Logistic regression analysis was used where the dependent variable was binary categorical (ovulation whether yes or no). Variables found (by univariate analysis) to be significantly associated with the dependent variable were entered into the regression model as independent variables (covariates). A ' $p$ ' value of $\leq 0.05$ was considered as statistically significant.

\section{Results}

The study included 143 infertile women with polycystic ovary syndrome. Their mean age \pm SD was $29.52 \pm 4.58$ years, ranging from 20 to 39 years. The median was 29 years. Table 1 shows that around half ( $45 \%)$ of the students aged $25-29$ years, and the duration of infertility of $64.3 \%$ of them was $\geq 5$ years. The type of infertility of the majority of the women (76.2\%) was primary. Regarding the menstrual pattern, it was irregular in the majority $(88.8 \%)$ of the women. It is evident that only $9.8 \%$ of the women were of normal weight, $30.1 \%$ were over-weight, and $60.1 \%$ were obese.

Table 2 shows that the rate of ovulation was significantly high among women with less than five years of infertility (76.5\%) compared with 50\% among women with $\geq 5$ years of infertility $(p=0.002)$. No significant association was detected between ovulation with age $(p=0.165)$, type of infertility $(p=0.264)$, menstrual pattern $(p=0.421)$, BMI $(p=0.138)$, hirsute $(\mathrm{p}=0.377)$, and acne $(\mathrm{p}=0.688)$.

The rate of infertility was significantly high $(79.2 \%)$ among women with $\mathrm{LH}$ level of more than $12 \mathrm{mIU} / \mathrm{ml}$ compared with $55.5 \%$ among women with LH level of $\leq 12 \mathrm{mIU} / \mathrm{ml}(\mathrm{p}=0.031)$. The rate of ovulation was also high (63.4\%) among women with free testosterone level of less than $4.5 \mathrm{ng} / \mathrm{ml}$ compared with $35 \%$ among 
women with free testosterone of $\geq 4.5 \mathrm{ng} / \mathrm{ml}$. Ovulation occurred in $66.7 \%$ of women with AMH level of less than $7.7 \mathrm{ng} / \mathrm{ml}$ compared with $50 \%$ among women with AMH level of $\geq 7.7 \mathrm{ng} / \mathrm{ml}$ ( $\mathrm{p}=0.044)$. No significant association was detected between the rate of ovulation with FAI $(p=0.096)$ and LH FSH ratio $(p=0.166)$.

Table 4 shows no significant differences between the means of hormones (SHBG, prolactin, and FSH) of women who have ovulated and the means of hormones of women who didn't ovulate $(\mathrm{p}=0.173, \mathrm{p}=0.598, \mathrm{p}=$ 0.0.058 respectively).
Regression analysis (Table 5) showed significantly higher rates of ovulation among women with less than five years duration of infertility $(\mathrm{OR}=3.35,95 \% \mathrm{CI}$ $=1.47-7.65)$, high $\mathrm{LH}$ of more than $12 \mathrm{mIU} / \mathrm{ml}(\mathrm{OR}=$ $4.18,95 \% \mathrm{CI}=1.28-13.63)$, low free testosterone of less than $4.5 \mathrm{ng} / \mathrm{ml}(\mathrm{OR}=3.22,95 \% \mathrm{CI}=1.08-9.59)$. No significant $(\mathrm{p}=0.078)$ association was detected between the ovulation rate and the AMH level, but it is evident that the OR was around 2 among women with AMH level of less than $7.7 \mathrm{ng} / \mathrm{ml}$.

\begin{tabular}{|c|c|c|}
\hline Age (years) & No. & $(\%)$ \\
\hline $20-24$ & 19 & $(13.3)$ \\
\hline $25-29$ & 65 & $(45.5)$ \\
\hline $30-34$ & 33 & $(23.1)$ \\
\hline $35-39$ & 26 & $(18.2)$ \\
\hline \multicolumn{3}{|c|}{ Duration of infertility (years) } \\
\hline$<5$ & 51 & $(35.7)$ \\
\hline$\geq 5$ & 92 & $(64.3)$ \\
\hline \multicolumn{3}{|c|}{ Type of infertility } \\
\hline Primary & 109 & $(76.2)$ \\
\hline Secondary & 34 & $(23.8)$ \\
\hline \multicolumn{3}{|c|}{ Menstrual pattern } \\
\hline Regular & 16 & $(11.2)$ \\
\hline Irregular & 127 & $(88.8)$ \\
\hline \multicolumn{3}{|c|}{ Body mass index (Kg/m2) } \\
\hline$<25$ & 14 & $(9.8)$ \\
\hline $25-29$ & 43 & $(30.1)$ \\
\hline$\geq 30$ & 86 & $(60.1)$ \\
\hline Total & 143 & $(100.0)$ \\
\hline
\end{tabular}


Table 2. Ovulation rate by the studied factors after LOD.

\begin{tabular}{|c|c|c|c|c|c|c|c|}
\hline & \multicolumn{2}{|c|}{ Ovulated } & \multicolumn{2}{|c|}{ Non ovulated } & \multicolumn{2}{|c|}{ Total } & \multirow[b]{2}{*}{$\mathbf{p}$} \\
\hline & No. & $(\%)$ & No. & $(\%)$ & No. & $(\%)$ & \\
\hline \multicolumn{8}{|c|}{ Age (years) } \\
\hline $20-24$ & 15 & $(78.9)$ & 4 & $(21.1)$ & 19 & $(100.0)$ & \\
\hline $25-29$ & 40 & $(61.5)$ & 25 & $(38.5)$ & 65 & $(100.0)$ & \\
\hline $30-34$ & 16 & $(48.5)$ & 17 & $(51.5)$ & 33 & $(100.0)$ & \\
\hline $35-39$ & 14 & $(53.8)$ & 12 & $(46.2)$ & 26 & $(100.0)$ & 0.165 \\
\hline \multicolumn{8}{|c|}{ Duration of infertility (years) } \\
\hline$<5$ & 39 & $(76.5)$ & 12 & $(23.5)$ & 51 & $(100.0)$ & \\
\hline$\geq 5$ & 46 & $(50.0)$ & 46 & $(50.0)$ & 92 & $(100.0)$ & 0.002 \\
\hline \multicolumn{8}{|c|}{ Type of infertility } \\
\hline Primary & 62 & $(56.9)$ & 47 & $(43.1)$ & 109 & $(100.0)$ & \\
\hline Secondary & 23 & $(67.6)$ & 11 & $(32.4)$ & 34 & $(100.0)$ & 0.264 \\
\hline \multicolumn{8}{|c|}{ Menstrual pattern } \\
\hline Regular & 11 & $(68.8)$ & 5 & $(31.3)$ & 16 & $(100.0)$ & \\
\hline Irregular & 74 & $(58.3)$ & 53 & $(41.7)$ & 127 & $(100.0)$ & 0.421 \\
\hline \multicolumn{8}{|l|}{ BMI } \\
\hline$<25$ & 11 & $(78.6)$ & 3 & $(21.4)$ & 14 & $(100.0)$ & \\
\hline $25-29$ & 28 & $(65.1)$ & 15 & $(34.9)$ & 43 & $(100.0)$ & \\
\hline$\geq 30$ & 46 & $(53.5)$ & 40 & $(46.5)$ & 86 & $(100.0)$ & 0.138 \\
\hline \multicolumn{8}{|l|}{ Hirsute } \\
\hline Yes & 67 & $(61.5)$ & 42 & $(38.5)$ & 109 & $(100.0)$ & \\
\hline No & 18 & $(52.9)$ & 16 & $(47.1)$ & 34 & $(100.0)$ & 0.377 \\
\hline \multicolumn{8}{|l|}{ Acne } \\
\hline Yes & 44 & $(57.9)$ & 32 & $(42.1)$ & 76 & $(100.0)$ & \\
\hline No & 41 & $(61.2)$ & 26 & $(38.8)$ & 67 & $(100.0)$ & 0.688 \\
\hline Total & 85 & $(59.4)$ & 58 & $(40.6)$ & 143 & $(100.0)$ & \\
\hline
\end{tabular}


Table 3. Ovulation rate by the hormone level after LOD.

\begin{tabular}{|c|c|c|c|c|c|c|c|}
\hline & \multicolumn{4}{|c|}{ Ovulation } & & & \\
\hline & \multicolumn{2}{|l|}{ Yes } & \multicolumn{2}{|l|}{ No } & \multicolumn{2}{|l|}{ Total } & \\
\hline & No. & $(\%)$ & No. & $(\%)$ & No. & (\%) & $\mathrm{p}$ \\
\hline \multicolumn{8}{|c|}{$\mathrm{LH} \mathrm{mIU} / \mathrm{ml}$} \\
\hline$\leq 12$ & 66 & (55.5) & 53 & $(44.5)$ & 119 & $(100.0)$ & \\
\hline$>12$ & 19 & $(79.2)$ & 5 & (20.8) & 24 & (100.0) & 0.031 \\
\hline \multicolumn{8}{|c|}{ Free testosterone $\mathrm{ng} / \mathrm{ml}$} \\
\hline$<4.5$ & 78 & (63.4) & 45 & (36.6) & 123 & (100.0) & \\
\hline$\geq 4.5$ & 7 & $(35.0)$ & 13 & $(65.0)$ & 20 & $(100.0)$ & 0.016 \\
\hline \multicolumn{8}{|c|}{$\mathrm{AMH} \mathrm{ng} / \mathrm{ml}$} \\
\hline$<7.7$ & 54 & (66.7) & 27 & (33.3) & 81 & (100.0) & \\
\hline$\geq 7.7$ & 31 & $(50.0)$ & 31 & $(50.0)$ & 62 & $(100.0)$ & 0.044 \\
\hline \multicolumn{8}{|l|}{ FAI } \\
\hline$<5$ & 8 & $(57.1)$ & 6 & $(42.9)$ & 14 & (100.0) & \\
\hline $5-14.9$ & 46 & (68.7) & 21 & $(31.3)$ & 67 & (100.0) & \\
\hline$\geq 15$ & 31 & $(50.0)$ & 31 & $(50.0)$ & 62 & $(100.0)$ & 0.096 \\
\hline \multicolumn{8}{|c|}{ LH FSH ratio } \\
\hline$<2$ & 27 & $(51.9)$ & 25 & $(48.1)$ & 52 & (100.0) & \\
\hline$\geq 2$ & 58 & (63.7) & 33 & (36.3) & 91 & $(100.0)$ & 0.166 \\
\hline Total & 85 & (59.4) & 58.0 & $(40.6)$ & 143.0 & $(100.0)$ & \\
\hline
\end{tabular}

Table 4. Means of hormones by ovulation status after LOD.

\begin{tabular}{|l|l|l|l|l|l|}
\hline & \multicolumn{2}{l|}{ Ovulation } & \multicolumn{2}{l|}{ No ovulation } & \\
\hline Hormones & Mean & $(+\mathrm{SD})$ & Mean & $(+\mathrm{SD})$ & P \\
\hline SHBG nmol/1 & 19.59 & $(+8.04)$ & 21.68 & $(+10.18)$ & 0.173 \\
\hline Prolactin ng/ml & 19.43 & $(+9.73)$ & 20.27 & $(+8.83)$ & 0.598 \\
\hline Serum FSH mIU/ml & 4.70 & $(+1.00)$ & 4.39 & $(+0.94)$ & 0.058 \\
\hline
\end{tabular}


Table 5. SPSS output of binary logistic regression analysis where ovulation was the dependent variable.

\begin{tabular}{|c|c|c|c|c|c|}
\hline & B & $\mathbf{p}$ & OR & \multicolumn{2}{|c|}{ 95\% C.I.for OR } \\
\hline \multicolumn{4}{|c|}{ Duration of infertility (years) } & Lower & Upper \\
\hline$<5$ & 1.21 & $<0.001$ & 3.35 & 1.47 & 7.65 \\
\hline$\geq 5$ (reference) & & & 1.00 & & \\
\hline \multicolumn{6}{|l|}{ LH } \\
\hline$>12$ & 1.43 & 0.018 & 4.18 & 1.28 & 13.63 \\
\hline$\leq 12($ reference $)$ & & & 1.00 & & \\
\hline \multicolumn{6}{|l|}{ AMH } \\
\hline$<7.7$ & 0.69 & 0.078 & 1.99 & 0.93 & 4.28 \\
\hline$\geq 7.7$ (reference) & & & 1.00 & & \\
\hline \multicolumn{6}{|l|}{ Free testosterone } \\
\hline$<4.5$ & 1.17 & 0.036 & 3.22 & 1.08 & 9.59 \\
\hline$\geq 4.5$ (reference) & & & 1.00 & & \\
\hline Constant & -1.75 & 0.003 & 0.17 & & \\
\hline
\end{tabular}

\section{Discussion}

Ovulation rate reported in our study was $59.4 \%$ and pregnancy rate $32.9 \%$ many studies recorded higher rates in their results $4,9,11$. For prediction of response we focused on ovulation being the primary outcome after treatment.

In the current study, there was no association between the age group, type of infertility, menstrual pattern, presence or absence of hirsute or acne and rates of ovulation after drilling, the same results recorded by other studies ${ }^{6,12}$ while in another study age $<30$ years considered as a significant predictor for success ${ }^{13}$ this difference may be due to that their studied population more in younger age. BMI exhibited a great variation regarding it is effect on the success of LOD, some authors found that lean women respond more than obese ${ }^{13,14}$, on the contrary an author correlated high BMI with the success ${ }^{12}$, although in our results and previous studies reported that BMI had no influence on overall ovulation rate ${ }^{11,15}$. Shorter duration of infertility $<5$ years appear to be the best determinant in the present study and before ${ }^{6,13,16}$, this is not in agreement with the a study of ${ }^{12}$ found no association, this can be explained that longer duration of subfertility may be associated with other causative factors and chronic anovulation needs more time for cure.

It was also noted that preoperative serum LH level were significantly higher among those who achieved ovulation after surgery with a " cut-off " of $12 \mathrm{mIU} / \mathrm{ml}$, this is in agreement with several other studies ${ }^{11,15}$ using the same value and same results, Logistic regression in the study of ${ }^{6,16}$ using $10 \mathrm{IU} / \mathrm{L}$ "cut-off " value also recognized high $\mathrm{LH}$ as a predicting factor for success.

Many researches considered AMH as a predicting factor for diagnosis and response to LOD, High AMH associated with poor response may be due to severity of the PCOS condition in these women. Although association of AMH and ovulation revealed significant $(p=0.044)$ in our data, but by regression analysis AMH is not regarded as a predicting factor. In contrary another author ${ }^{7}$ reported that AMH affect the outcome after LOD using the same "cut-off" value $(7.7 \mathrm{ng} / \mathrm{ml})$, a possible explanation is that number of the holes by electrocautery and degree of tissue destruction may affect the success. 
Favorable outcome was recorded in those with low free testosterone level $<4.5 \mathrm{ng} / \mathrm{m}$, this result was consistent with ${ }^{6}$. Although this is in disagreement with earlier results ${ }^{15,16}$ can be explained by smaller sample size in their study or inadequate destruction of androgen producing ovarian tissue, so an adjusted thermal dose based on ovarian volume ${ }^{17}$ to be fully elucidated.

On the other hand LH/FSH ratio, FSH, SHBG, FAI and prolactin have no impact on the outcome after LOD, AL-Ojaimi ${ }^{12}$ also recorded no significant association with FSH and prolactin level while LH:FSH ratio showed significant while Dubela et $\mathrm{al}^{14}$ found that high SHBG is significant for success. Inability to follow-up patients for longer periods to record pregnancy and livebirth rates was the main limitation of our study.

\section{Conclusions}

Identifying factors that affect outcome of LOD helps in increasing success rate, it is an important issue not only to improve outcome but also to avoid unnecessary surgery and it is complications. Higher rate of ovulation found among those with less than 5 years duration of infertility, $\mathrm{LH}>12 \mathrm{mIU} / \mathrm{ml}$ and free testosterone < $4.5 \mathrm{ng} / \mathrm{ml}$.

Conflicts of Interest: No conflicts of interest

Ethical Clearance: The Research Ethics Committee of HMU, College of Medicine, approved the study proposal.

\section{Source of Funding: Not}

\section{References}

1. The Thessaloniki ESHRE/ASRM-Sponsored PCOS Consensus Workshop Group, Consensus on infertility treatment related to polycystic ovary syndrome, Human Reproduction, Volume 23, Issue 3, March 2008, Pages 462-477.

2. The Rotterdam ESHRE/ASRM-Sponsored PCOS Consensus Workshop Group. Revised 2003 consensus on diagnostic criteria and long-term health risks related to polycystic ovary syndrome. Fertil Steril 2004;81:19-25.

3. Stein IF, Leventhal ML. Amenorrhea associated with bilateral polycystic ovaries. Am J Obstet Gynecol; 1935; 29:181-91.

4. Gjonnaess H. Polycystic ovarian syndrome treated by ovarian electrocautery through the laparoscope.
Fertil Steril.1984;41:20-25.

5. Abu Hashim H, Al-Inany H, De Vos M, Tournaye H. Three decades after Gjönnaess's laparoscopic ovarian drilling for treatment of PCOS; what do we know? An evidence-based approach. Arch Gynecol Obstet. 2013;288:409-22.

6. Amer SA, Li TC, Ledger WL. Ovulation induction using laparoscopic ovarian drilling in women with polycystic ovarian syndrome: Predictors of success. Hum Reprod. 2004;19:1719-24.

7. Amer SA, Li TC, Ledger WL. The value of measuring anti-Mullerian hormone in women with anovulatory polycystic ovary syndrome undergoing laparoscopic ovarian diathermy. Hum Reprod. 2009;24:2760-6.

8. Balen A, Homburg R, Franks S. Defining polycystic ovary syndrome. BMJ; 200 9;338:2968.

9. Armar NA, McGarrigle HH, Honour J, Holownia P, Jacobs HS, Lachelin GC. Laparoscopic ovarian diathermy in the management of anovulatory infertility in women with polycystic ovaries: Endocrine changes and clinical outcome. Fetil Steril 1990;53:45-9.

10. Aakvaag A, Gjonnaess H. Hormonal response to electrocautery of the ovary in patients with polycystic ovarian disease, Br J Obstet Gynaecol. 1985; vol. 92 (pg. 1258-1264).

11. Ott J, Wirth S, Nouri K, Kurz C, Mayerhofer $\mathrm{K}$, Huber $\mathrm{JC}$, et al. Luteinizing hormone and androstendione are independent predictors of ovulation after laparoscopic ovarian drilling: a retrospective cohort study. Reprod Biol Endocrinol RBE 2009;7:153.

12. Al-Ojaimi EH. Endocrine changes after laparoscopic ovarian drilling in clomiphene citrateresistant women with polycystic ovarian syndrome. Saudi Med J. 2004; 25(8):1032-9.

13. Baghdadi LR, Abu Hashim H, Amer SAK, Palomba S, Falbo A, Al-Ojaimi E, et al. Impact of obesity on reproductive outcomes after ovarian ablative therapy in PCOS: a collaborative meta-analysis. Reprod Biomed Online 2012;25(3):227-41.

14. Duleba AJ, Banaszewska B, Spaczynski RZ, Pawelczyk L. Success of laparoscopic ovarian wedge resection is related to obesity, lipid profile, and insulin levels. Fertil Steril. 2003;79:1008-14.

15. Abdel GA, Khatim MS, Alnaser HM, Mowafi RS, Shaw RW. Ovarian electrocautery: responders 
versus non-responders. Gynecol Endocrinol 1993;7:43-48.

16. Li TC, Saravelos H, Chow MS, Chisabingo R, Cooke ID. Factors affecting the outcome of laparoscopic ovarian drilling for polycystic ovarian syndrome in women with anovulatory infertility. Br J Obstet Gynaecol 1998;105(3):338-44.

17. Zakherah MS, Kamal MM, Hamed HO. Laparoscopic ovarian drilling in polycystic ovary syndrome: efficacy of adjusted thermal dose based on ovarian volume. Fertil Steril 2011;95(3):11158 . 